\title{
Impaired Oral Tolerance in ASD Children with Food Protein Induced Enterocolitis Syndrome (FPIES) - Altered Innate and Adaptive Immune Responses in ASD Children Recovered from FPIES in Comparison with non-ASD/FPIES and ASD/non-FPIES Children
}

\author{
Harumi Jyonouchi, Lee Geng, Pamella Kattouf, \\ Deanna L. Streck and Gokce Toruner \\ University of Dentistry and Medicine of New Jersey, New Jersey Medical School, \\ Newark, NJ, \\ USA
}

\section{Introduction}

The gut mucosal immune system has to maintain an intricate immune homeostasis by maintaining tolerance to macronutrients, commensal flora, and other harmless molecules in the gut lumen while exerting effective immune defense against pathogenic microbes. It takes the first few years of life to establish this intricate immune homeostasis and until then the gut mucosal immune system is rather error-prone. This is reflected in the fact that young infants and children often suffer from temporary intolerance to common food proteins (FP), e.g. food allergy (FA). During this period, most FA manifests as delayed type FA, mediated by cellular immune responses - often called FP induced enterocolitis syndrome (FPIES) (Jyonouchi, 2008; Nowak-Wegrzyn and Muraro, 2009; Sicherer et al., 1998). Although FPIES seldom cause fatal anaphylaxis, as opposed to IgE-mediated FA, this condition is often under-diagnosed and under-treated. This is, in part, due to the delayed onset of symptoms that renders clinical connection more difficult, as well as, the lack of commercially available diagnostic measures. This is in contrast to IgE mediated FA in which a causal relationship is apparent in many cases and reactivity to food allergens is easily detected with prick skin test (PST) and/or presence of FA specific IgE antibody. The delay in the onset of symptoms of FPIES makes it especially difficult to diagnose FPIES clinically in infants and young children, as well as those with limited expressive language including children with autism spectrum disorders (ASD). In general, FPIES has an excellent prognosis provided there is timely implementation of avoidance measures against offending food (Jyonouchi, 2008; Nowak-Wegrzyn and Muraro, 2009). However, delayed diagnosis/treatment of FPIES can lead to failure to thrive (FTT), protein losing enteropathy, and possibly other irreversible complications. 
GI symptoms are frequently observed in ASD (Buie et al., 2010). A role of FPIES has been suspected to play a role in GI symptoms observed in ASD children, since many parents of ASD children with GI symptoms report favorable responses to the casein-free, gluten-free (cf/gf) diet. We have reported previously that FPIES accounts for the GI symptoms experienced in many young ASD children (Jyonouchi et al., 2005). We have also observed that resolution of GI symptoms in ASD/FPIES children following implementation of avoidance of offending food was associated with improvement of certain behavioral symptoms, (Jyonouchi H, 2007).

However, in our observation, even after recovering from FPIES, some ASD children continue to suffer from recurrent or persistent GI symptoms. We also observed that flare ups of GI symptoms in these ASD/FPIES children are usually triggered by GI insults such as microbial gastroenteritis and prolonged oral antibiosis. Such 'treatment-resistant' GI symptoms after implementation of appropriate avoidance measures are less frequently observed in non-ASD/FPIES children. Since diagnosis of FPIES in ASD children are typically delayed partly due to their limited expressive language, it may be argued that this is simply reflecting a longer period of GI inflammation in ASD/FPIES children than in nonASD/FPIES children. However, ASD/FPIES children with persistent GI symptoms also often exhibit other co-morbid conditions such as recurrent respiratory infection, adverse reaction to multiple medications, and seizure disorders, in our observation. Thus we hypothesized that 1) oral tolerance to FP and commensal flora is fragile and easily broken in ASD/FPIES children with persistent GI symptoms, and 2) this is associated with altered innate immune and adaptive immune responses in these 'treatment-resistant' ASD/FPIES children. We also hypothesized that evidence of impaired oral tolerance can be detected by studying peripheral blood mononuclear cells (PBMCs). These hypotheses are based on the facts that 1) aberrant immune responses to commensal flora is implicated with onset of chronic inflammatory conditions in the gut (Schirbel and Fiocchi, 2010), 2) plasticity of Thelper (Th) cell differentiation is not as definite as initially thought and aberrant innate immune responses and altered gut microbiota can hinder development of gut immune homeostasis (Lee and Mazmanian, 2010; Zhou et al., 2009), and 3) FP specific Th cells circulate in the peripheral blood (PB) (Karlsson et al., 2004).

This study focused on ASD/FPIES children and non-ASD/FPIES children who have already been treated for FPIES. In these subjects, we assessed innate immune responses, Th cell polarization, and $\mathrm{T}$ cell functions in comparison with normal control children. Our results indicate that a subset of ASD/FPIES children with persistent GI symptoms revealed a different pattern of innate and adaptive immune responses as compared to both ASD/FPIES or non-ASD/FPIES children.

\section{Materials and methods}

\subsection{The study subjects}

The study subjects were recruited following the study protocols approved by the Institutional Review Board, University of Medicine and Dentistry of New Jersey-New Jersey Medical School (UMDNJ-NJMS). Blood samples were collected after obtainment of signed parental consent forms. Signed assent forms were also obtained, if applicable, in children older than 7 years of age.

A total of 45 ASD/FPIES children who have been treated for FPIES were included in this study in addition to control ASD/non-FPIES $(\mathrm{N}=24)$, non-ASD/FPIES $(\mathrm{N}=26)$, and typically 
growing, healthy control children without FPIES (N=43). Among 45 ASD/FPIES children, 16 children revealed persistent or recurrent GI symptoms with suboptimal responses to dietary intervention measures (avoidance of offending food). These children are categorized as ASDimmune subtype (ASD-IS), since their behavioral and GI symptoms flared up repeatedly following immune insults such as viral infection. The demographics of the study subjects are summarized in Table 1. Non-ASD/FPIES children recruited to the study were also already treated for FPIES with implementation of appropriate avoidance measures. ASD and FPIES children were recruited in the Pediatric Allergy/Immunology Clinic at our institution. Normal healthy control and ASD/non-FPIES children were recruited in the Subspecialty Clinic at UMDNJ-NJMS where subspecialties include allergy/immunology, cardiology, developmental pediatrics, endocrinology, genetics, gastroenterology, nephrology, pulmonology, and general pediatrics. In most cases, blood samples were obtained when they were medically indicated to have venipuncture for routine blood work or general health screening. At the time of sample obtainment, all the subjects were examined to ensure absence of active infection.

\begin{tabular}{|l|c|c|c|}
\hline & $\begin{array}{c}\text { Age (yr) } \\
\text { median (range) }\end{array}$ & Sex (male: female) & Ethnicity \\
\hline ASD-IS (N=16) & $9.7(5-15.9)$ & $16: 0$ & $\begin{array}{c}13 \mathrm{~W}, 1 \mathrm{AA}, 1 \\
\text { mixed, } 1 \text { Asian }\end{array}$ \\
\hline ASD/FPIES (N=29) & $6.2(3-17.3)$ & $25: 4$ & $\begin{array}{c}24 \mathrm{~W}, 1 \mathrm{AA}, 1 \\
\text { mixed, 3 Asians }\end{array}$ \\
\hline ASD/non-FPIES (N-24) & $6.5(3-15.9)$ & $20: 4$ & $\begin{array}{c}16 \mathrm{~W}, 1 \mathrm{AA}, 2 \\
\text { mixed, 5 Asians }\end{array}$ \\
\hline Non-ASD/FPIES (N=26) & $4.2(1.7-15.9)$ & $17: 9$ & $\begin{array}{c}22 \mathrm{~W}, 2 \text { mixed, } 2 \\
\text { Asians }\end{array}$ \\
\hline Normal control (N=43) & $8.5(1-17.8)$ & $29: 14$ & $33 \mathrm{~W}, 6$ AA, 4 mixed \\
\hline
\end{tabular}

${ }^{1}$ Abbreviations used: AA (African Americans), W (Caucasians)

Table 1. Demographics of the pediatric study subjects.

\subsubsection{ASD diagnosis}

ASD diagnosis was made or ascertained by DSM-IV (Diagnostic and Statistical Manual of Mental Disorders IV) criteria, ADI-R (Autism Diagnostic Interview-Revised), and/or ADOS (Autism Diagnostic Observational Schedules). All the ASD children recruited to this study were those with established autism diagnosis from established autism diagnostic centers including ours at UMDNJ.

\subsubsection{Diagnosis of atopic disorders}

Allergic rhinitis (AR), allergic conjunctivitis (AC) were diagnosed with positive prick skin test reactivity and/or presence of allergen-specific IgE accompanied by clinical features consistent with AR and AC (Butrus and Portela, 2005; Nassef et al., 2006). Asthma diagnosis was based on NIH guideline criteria (National Heart, Lung, Blood Institute, 2007). Asthma without prick skin test reactivity and/or allergen-specific IgE antibody was categorized as non-atopic asthma (Nassef et al., 2006) 


\subsubsection{Diagnosis of FPIES}

FPIES to common food proteins (FPs; cow's milk protein, wheat, and soy) was diagnosed using the following diagnostic criteria: 1) presence of objective GI symptoms (diarrhea, loose stool, and constipation) which resolved with avoidance of causative FPs (Sicherer and Sampson, 2006), 2) delayed (more than $6 \mathrm{~h}$ ) onset of GI symptoms following exposure to offending FPs after resolution of GI symptoms, and 3) cellular immune reactivity to offending FPs defined as the production of more than 1 standard deviation (SD) + control mean value of TNF- $\alpha$ and/or IL-12 by PBMCs with stimuli of causative DPs (Jyonouchi et al., 2005).

Diagnoses of other GI conditions were ascertained by reviewing medical charts and previous laboratory findings. Persistent GI symptoms are defined as lack of complete resolution of GI symptoms following introduction of appropriate restricted diet (avoidance of offending food) with persistent unformed stools, loose stool, and constipation alternating with diarrhea or loose stool. It is of note that these ASD/FPIES children with persistent GI symptoms (e.g. ASD-IS children) often revealed beneficial effects from oral anti-fungal medications (fluconazole or nystatin) and antibiotics (usually metronidazole) with improvement of GI symptoms. However, the beneficial effects of anti-fungals and antibiotics are generally short-lived and repeated courses of these therapies are often required, along with the persistent use of probiotics to control GI symptoms.

\subsection{Cultures of PBMCs}

PBMCs were isolated by Ficoll-Hypaque density gradient centrifugation. Innate immune responses were assessed by incubating PBMCs $\left(10^{6}\right.$ cells $\left./ \mathrm{ml}\right)$ overnight with TLR4 agonist (LPS; $0.1 \mu \mathrm{g} / \mathrm{ml}$, GIBCO-BRL, Gaithersburg, MD), TLR2/6 agonist (zymosan; $50 \mu \mathrm{g} / \mathrm{ml}$, Sigma-Aldrich, St. Luis, Mo), TLR3 agonist (Poly I:C, $0.1 \mu \mathrm{g} / \mathrm{ml}$, Sigma-Aldrich), and TLR7/ 8 agonist (CL097, water-soluble derivative of imidazoquinoline, $20 \mu \mathrm{M}$, InvivoGen, San Diego, CA) in RPMI 1640 with additives as previously described (Jyonouchi et al., 2001). Overnight incubation was adequate to induce the optimal responses in this setting. Levels of proinflammatory [tumor necrosis factor- $\alpha$ (TNF- $\alpha$ ), interleukin (IL)-1 $\beta$, IL-6, IL-12p40, and IL-23] and counter-regulatory [IL-10, transforming growth factor- $\beta$ (TGF- $\beta$ ) and soluble TNF receptor II (sTNFRII)] cytokines in culture supernatant were then measured by an enzyme-linked immunosorbent assay (ELISA).

Cellular reactivity to $\mathrm{T}$ cell stimulants was assessed by incubating PBMCs $\left(10^{6}\right.$ cells $\left./ \mathrm{ml}\right)$ with $\mathrm{T}$ cell mitogens [Con A $(2 \mu \mathrm{g} / \mathrm{ml})$ and PHA $(5 \mu \mathrm{g} / \mathrm{ml})$ ], recall antigens (Ags)[soy protein $(100 \mu \mathrm{g} / \mathrm{ml})$, B-lactoglobulin (BLG; $10 \mu \mathrm{g} / \mathrm{ml})$ Sigma-Aldrich, candida Ag $(5 \mu \mathrm{g} / \mathrm{ml})$, dust mite $(5 \mu \mathrm{l} / \mathrm{ml})$ Greer, Lenoir, $\mathrm{NC}$, tetanus toxoid $(1: 5000)]$, and IFN- $\gamma$ inducing cytokines [IL-12p70 (0.2 ng/ml, BD Biosciences, San Diego, CA), IL-18 (1 ng/ml, BD Biosciences) for 4 days and measuring levels of IFN- $\gamma$, TNF-a, IL-5, IL-10, IL-12p40, and IL17 in the culture supernatant (Jyonouchi et al., 2005). Initial titration studies showed that a four day incubation period resulted in the optimal production of these cytokines, in this setting.

Cytokine levels were measured by ELISA, using OptEIA ${ }^{\mathrm{TM}}$ Reagent Sets (BD Biosciences) for IFN-ү, IL-1B, IL-5, IL-6, IL-10, IL-12p40, and TNF-a, and ELISA reagent set (R \& D, Minneapolis, MN) for sTNFRII, IL-17 (IL-17A), and TGF-ß. IL-23 ELISA kit was purchased from eBiosciences, San Diego, CA. Intra- and inter-variations of cytokine levels were less than $5 \%$. 


\subsection{Flow cytometry}

For intracellular cytokine staining in $\mathrm{CD}^{+} \mathrm{T}$ cells, the following fluorochrome-conjugated monoclonal antibodies were used: CD4-PerCp, IFN- $\gamma-P E-C y 7$, IL-17-PE, IL-4-FITC, IL-10Pacific Blue (all from eBiosicences), and TGF-B-APC (R \& D, Minneapolis, MN). PBMCs were incubated at $37^{\circ} \mathrm{C}$ overnight $(16 \mathrm{~h})$ with medium alone, Staphylococcal enterotoxin B (5 $\mu \mathrm{g} / \mathrm{mL}$, Sigma-Aldrich), or candida Ag $(5 \mu \mathrm{g} / \mathrm{ml}$, Greer) in the presence of Brefeldin A (BFA; $5 \mu \mathrm{g} / \mathrm{ml}$, Sigma-Aldrich), anti-CD28 (1 $\mu \mathrm{g} / \mathrm{ml}$, eBiosciences), and anti-CD49 $(1 \mu \mathrm{g} / \mathrm{ml}$, eBiosciences). The same culture medium used for the cytokine production assay was utilized. Then PBMCs were permeabilized (permeabilization buffer, BD Biosciences) and stained with the above described antibodies. All flow cytometry was conducted by using FACSVantage SE TM (BD Biosciences) and the data were analyzed with the CellQuest software (BD Biosciences) and FlowJo (TreeStar, Ashland, OR).

\subsection{Transcription profiling}

PB monocytes were purified using an immuno-affinity column following the company's instructions (MACS monocytes isolation kit, Miltenyi Biotec, Auburn, CA). Total RNA were extracted by the RNA easy kit (Quiagen, Valencia, CA). RNA labelling and hybridizations on Agilent Human $4 \times 44 \mathrm{~K}$ arrays (Agilent, Lexington, MA) were done using the Agilent One-Color Microarray-Based Gene Expression Analysis Ver 5.5 protocol (Agilent). All slides were scanned by an Agilent Scanner and normalized numerical data were obtained by Agilent Feature extraction software 9.5.

\subsection{Statistical analysis}

For comparison of test values with control values, a Wilcoxon signed rank test was used. For comparison of values of multiple groups, a Kruskall-Wallis test was used. A Chi square $\left(X^{2}\right)$ test was used to examine the difference in frequency. These tests were performed using R.2.10.1 (R-Development Core Team 2009). A p value of $<0.05$ was considered to be statistically significant. For the analysis of microarrays experiments, Gene Spring GX v11 software (Agilent) was used. After filtering for "present" calls in at least $20 \%$ of samples, fold change analysis were performed for group for comparisons on 26992 probes. Genes with at least two fold changes, as compared to controls, are determined to be either upregulated or down-regulated. Using a specific module of GeneSpring software (Agilent), pathways enrichment analysis on those genes was performed to see if there is a statistically significant enrichment $(p<0.05)$ for specific BioPax pathways.

\section{Results}

\subsection{Clinical features}

Prevalence of common childhood disorders in the study groups is shown in Table 2. The prevalence of allergic rhinoconjunctivitis and asthma in ASD-IS, ASD/FPIES, ASD/nonFPIES, as well as in non-ASD/FPIES children was found to be similar to what is reported in general population (Table 2) (Akinbami et al., 2011; Singh et al., 2010). However, ASD-IS children revealed a higher prevalence of recurrent infection [recurrent otitis media (ROM) and chronic rhinosinusitis (CRS)] than other study groups (Table 2). It is of note, that 3 subjects out of these 6 ASD-IS children with recurrent infection were diagnosed with specific polysaccharide antibody deficiency (SPAD). In contrast, non-ASD/FPIES children seldom revealed chronic infection. Around $10 \%$ of ASD/FPIES and ASD/non-FPIES children had history of ROM but they did not suffer from CRS and they are responsive to 
the first-line antibiotics such as amoxicillin. It remains to be seen whether apparent higher prevalence of ROM in the ASD children in our study is associated with under-diagnosis or under-treatment, secondary to their limited expressive language.

\begin{tabular}{|l|c|c|c|c|}
\hline & AR+AC & Asthma & ROM/CRS & $\begin{array}{c}\text { Seizure } \\
\text { disorders }\end{array}$ \\
\hline $\begin{array}{l}\text { ASD-IS } \\
(\mathrm{N}=16)\end{array}$ & $4(25.0 \%)$ & $3(18.8 \%)^{4}$ & $6^{2}(37.5 \%)$ & $2(12.5 \%)$ \\
\hline $\begin{array}{l}\text { ASD/FPIES } \\
(\mathrm{N}=29)\end{array}$ & $4(13.8 \%)$ & $3(10.3 \%)$ & $4^{3}(13.8 \%)$ & $1(3.4 \%)$ \\
\hline $\begin{array}{l}\text { ASD/non-FPIES } \\
(\mathrm{N}=24)\end{array}$ & $5(20.8 \%)$ & $2 / 24(8.3 \%)$ & $2(8.3 \%)$ & 0 \\
\hline $\begin{array}{l}\text { Non-ASD/FPIES } \\
(\mathrm{N}=26)\end{array}$ & $6(23.1 \%)$ & $3 / 26(11.5 \%)$ & $1(0.4 \%)$ & 0 \\
\hline $\begin{array}{l}\text { Normal control } \\
(\mathrm{N}=43)\end{array}$ & $8(18.6 \%)$ & $5(11.6 \%)$ & 0 & 0 \\
\hline
\end{tabular}

${ }^{1}$ Abbreviations used: $\mathrm{AR}+\mathrm{AC}$, allergic rhinoconjunctivitis, $\mathrm{ROM}$, recurrent otitis media, CRS, chronic rhinosinusitis

${ }^{2}$ Among 6 subjects with recurrent ROM and CRS, 3 subjects were diagnosed with specific polysaccharide antibody deficiency (SPAD).

${ }^{3}$ One patient was diagnosed with SPAD.

${ }^{4} \mathrm{All} 3$ asthma patients are diagnosed with SPAD and asthma is considered as non-atopic asthma triggered by infection.

Table 2. Prevalence of co-morbid condition in the study subjects.

\subsection{Innate immune responses}

In response to a TLR4 agonist (LPS), ASD/FPIES PBMCs revealed lower TNF-a and IL-12 production than normal controls (Fig. 1). Non-ASD/FPIES PBMCs also revealed similar tendencies, however, the ASD/non-FPIES and ASD-IS cells did not differ from normal controls in the production of these cytokines (Fig. 1). IL-23 production with a TLR4 agonist

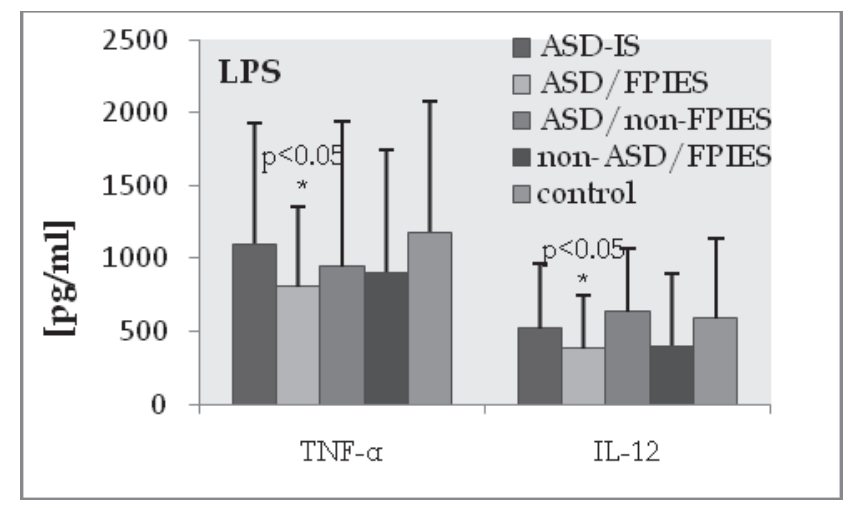

Fig. 1. Production of TNF-a and IL- 12 by PBMCs $\left(10^{6}\right.$ cells $\left./ \mathrm{ml}\right)$ from the study groups following overnight incubation with a TLR4 agonist (LPS). *; lower than normal controls by Wilcoxon signed rank test. 
was lower in both the ASD-IS and ASD/FPIES groups than normal controls (Fig. 2). We also observed lower production of IL-12 (with a TLR9 agonist) and IL-1ß (in the absence of stimuli and with a dectin 1 agonist) in the ASD-IS group. This was not observed in any other study groups (Figs. 2-3). IL-6 production without stimuli and in response to a TLR9 agonist were also the lowest in the ASD-IS group (Fig.3). ASD/FPIES but not nonASD/FPIES PBMCs revealed a similar tendency. However, this was less evident than in the ASD-IS cells (Fig. 3). Non-ASD/FPIES PBMCs revealed higher TGF- $B$ production with a TLR2/ 6 agonist than normal controls (Fig. 3). Taken together, our results indicate that ASDIS, ASD/FPIES, and non-ASD/FPIES children reveals different patterns of cytokine production in response to TLR agonists.

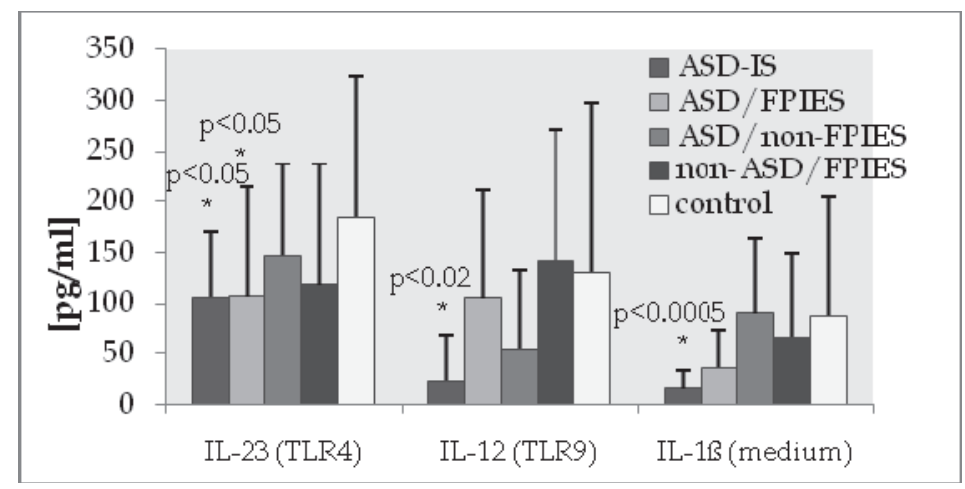

Fig. 2. Production of IL-23, IL-12, and IL- $1 \beta$ by PBMCs $\left(10^{6}\right.$ cells $\left./ \mathrm{ml}\right)$ in responses to TLR agonists as shown in the figure. *; significantly lower than normal controls by Wilcoxon signed rank test. IL-1 $\beta$ production was obtained when cells were cultured in the medium without a stimulus.

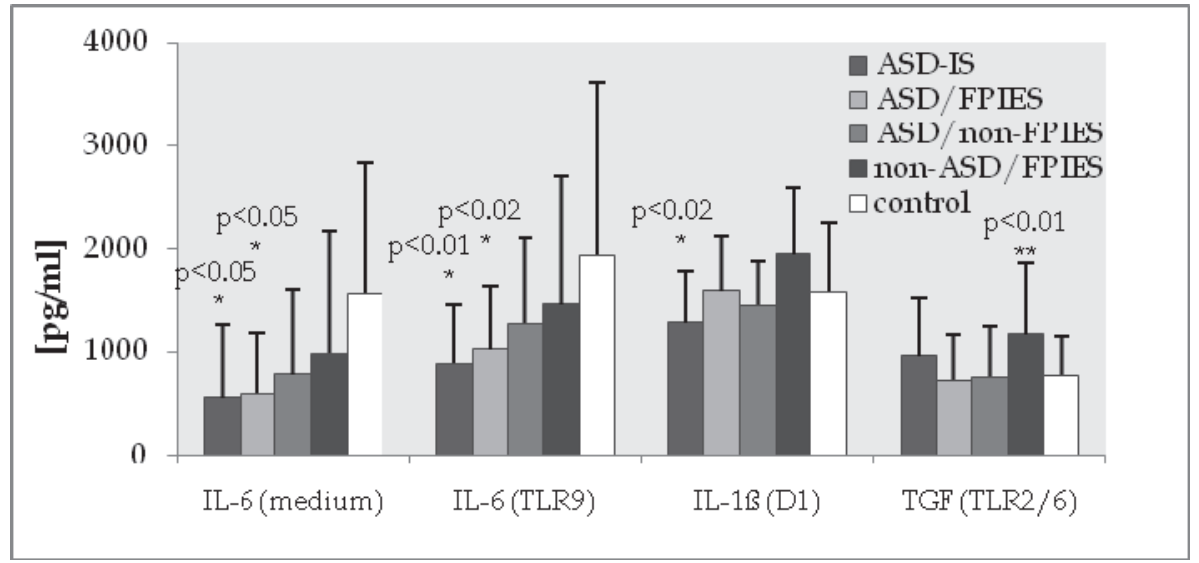

Fig. 3. Production of IL-6, IL-1 $\beta$, and TGF- $\beta$ by PBMCs $\left(10^{6}\right.$ cells $\left./ \mathrm{ml}\right)$ when incubated overnight with medium only (IL-6), TLR9 agonist (IL-6), Dectin-1 agonist (D1 - IL-1 $\beta$ ), and TLR2/ 6 agonist (TGF- $\beta$ ). *; significantly lower as compared to normal controls by Wilcoxon signed rank test. .**; significantly higher than normal controls by Wilcoxon signed rank test. 


\subsection{Adaptive immune responses}

No significant differences were observed among the study groups in responses to stimuli of $\mathrm{T}$ cell mitogens or recall antigens via vaccination (tetanus toxoid) or respiratory tract (dust mite). However, when PBMC responses to gut luminal Ags were tested, we observed a higher IL-5 production (with candida Ag) in non-ASD/FPIES children, while IL-17 production with B-LG and candida Ag were higher in the ASD-IS group as compared to the non-ASD/FPIES group (Fig. 4). Such increase in IL-17 production was not observed in ASD/FPIES children (Fig. 4). Moreover, IL-10 production was lower in the ASD-IS children without stimuli as well as in response to candida Ag (Fig. 5). We also assessed frequency of Th cell subsets following stimulation of PBMCs with a polyclonal $\mathrm{T}$ cell stimulant (SEB) overnight by measuring intracellular expression of Th-lineage specific cytokines in $\mathrm{CD} 4^{+} \mathrm{T}$ cells. Both the ASD-IS and ASD/FPIES groups revealed a lower frequency of IFN- $\gamma^{+}$Th1 cells than controls (Fig. 6). Frequency of IL-17+ Th17 cells were also lower in the ASD/FPIES group but not in ASD-IS or non-ASD/FPIES children. Our results also indicated differences in $\mathrm{T}$ cell responses in the study groups.

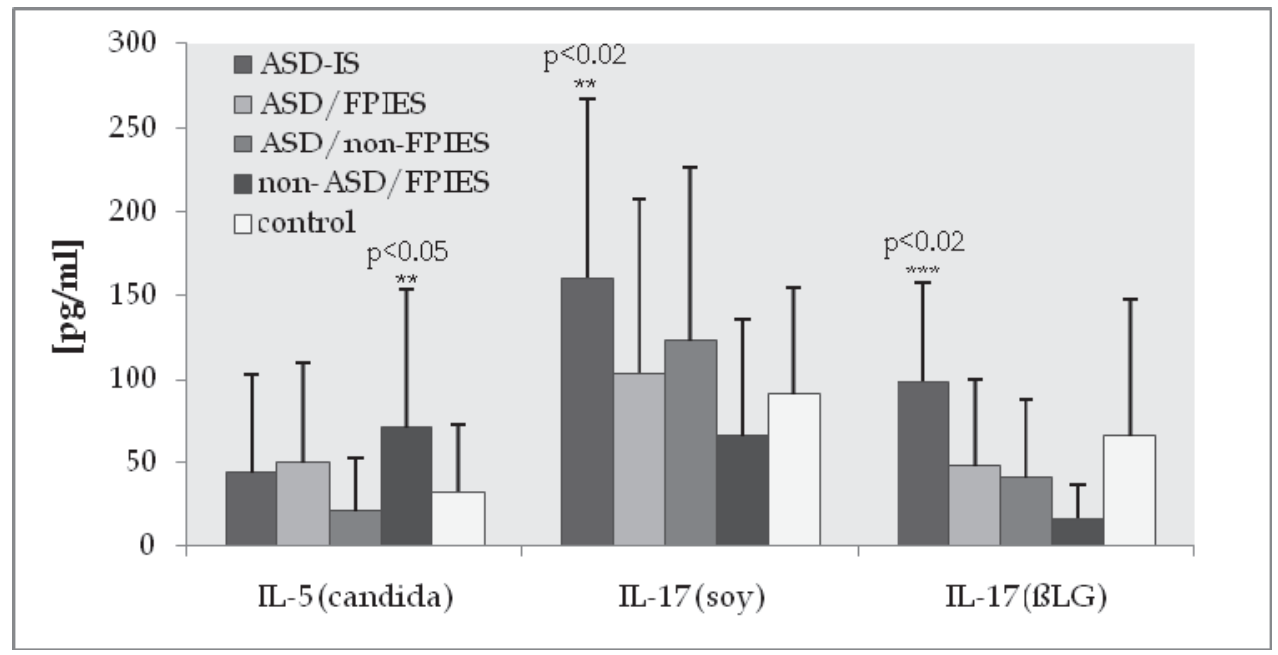

Fig. 4. Production of IL-5 and IL-17 in response to gut luminal antigens as shown in Figure. $\beta$ LG; $\beta$-lactoglobulin. PBMCs (106 cells $/ \mathrm{ml}$ ) were incubated for 4 days with these luminal antigens. **; significantly higher than normal controls by by Wilcoxon signed rank test. ***; significantly higher than non-ASD/FPIES, ASD/non-FPIES, ASD/FPIES controls by Wilcoxon signed rank test.

\subsection{Transcription profiling results}

Transcript profiles of PB monocytes were tested in 16 ASD-IS, 14 ASD/FPIES, 16 ASD/nonFPIES, and 26 normal control children. The changes of transcript expression are summarized in Table 3. As compared to ASD/FPIES, ASD/non-FPIES, and normal control groups, ASDIS PB monocytes revealed that a large numbers of genes are up- or down-regulated over 2fold and the difference was most significant when compared to normal controls (Table 3). ASD/FPIES children also revealed changes in gene expression as compared to ASD/non- 


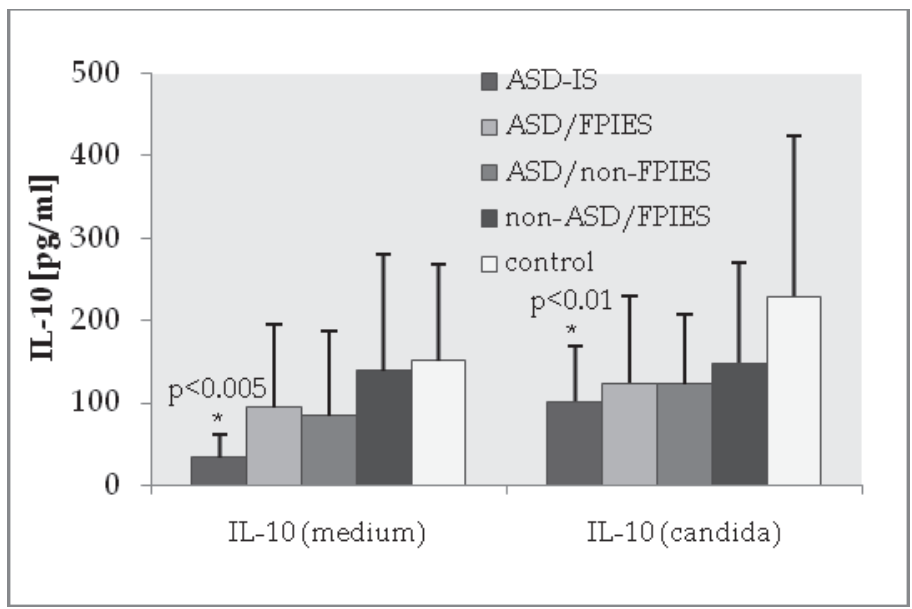

Fig. 5. IL-10 production when PBMCs (106 cells $/ \mathrm{ml})$ were cultured for 4 days with candida Ag or medium only in the study groups. *; significantly lower than normal controls by Wilcoxon signed rank test.

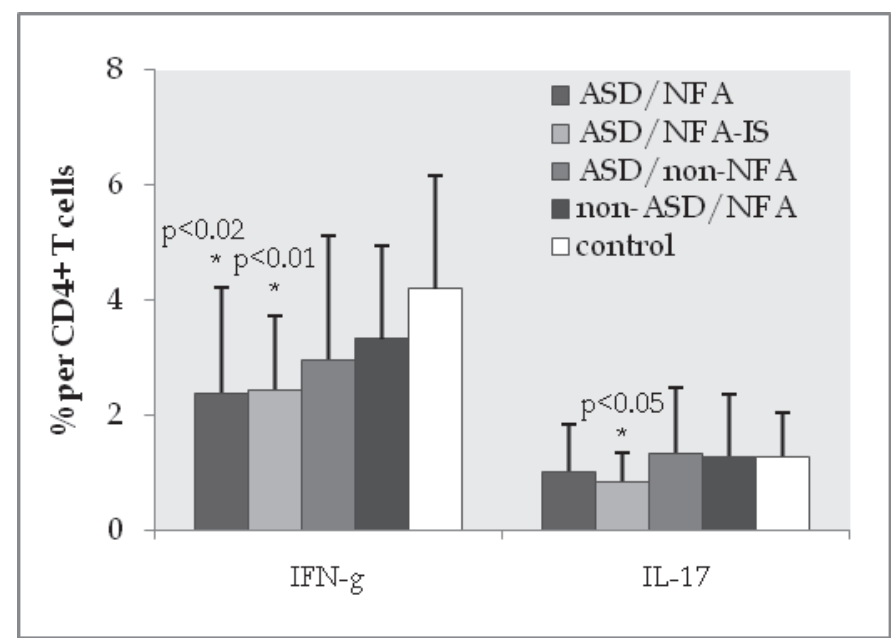

Fig. 6. Percent of IFN- $\gamma^{+}$and IL- $17^{+} \mathrm{CD} 4^{+}$T-helper cells per total CD4 ${ }^{+}$cells in PBMCs obtained from the study groups. PBMCs were incubated overnight with SEB and intracellular cytokine expression was assessed by flow cytometry as detailed in the Materials and Methods section. *; lower than normal controls by Wilcoxon signed rank test.

FPIES and normal controls. However, the numbers of genes up- or down-regulated were not as many as seen in ASD-IS children (Table 3). ASD/non-FPIES children also revealed changes in gene expression in a large number of genes as compared to controls (Table 3). Notable findings are the down-regulated expression of cytokines and chemokines in ASD-IS, as well as ASD/FPIES children, as compared to ASD/non-FPIES children. This finding is consistent with those from the bioassays. CCL7 expression was down regulated in ASD/non-FPIES 
children as compared to all the study groups. The pathway analysis did not reveal any significant enrichment of genes in known signaling pathways. GO analysis revealed significant differences in the ASD/FPIES and ASD/non-FPIES groups; changes were evident in inflammatory processes and cytokine/chemokine signaling pathways. In comparison with normal controls, both ASD-IS and ASD/FPIES patients did not reveal significant changes.

\begin{tabular}{|c|c|c|}
\hline Group & $\begin{array}{c}\text { Numbers of genes Up- } \\
\text { regulated }\end{array}$ & $\begin{array}{c}\text { Numbers of genes } \\
\text { down-regulated }\end{array}$ \\
\hline ASD-IS & $231^{1}$ & 61 \\
Vs. ASD/FPIES & 784 & $148^{2}$ \\
Vs. ASD/non-FPIES & 1341 & 617 \\
Vs. control & & $92^{2}$ \\
& 251 & 191 \\
\hline ASD/FPIES & 223 & \\
Vs. ASD/non-FPIES & & $1152^{3}$ \\
\hline ASD/non-FPIES & 7233 & \\
Vs. control & & \\
\hline
\end{tabular}

${ }^{1}$ CCR7 and CCL7 are up-regulated in ASD-IS monocytes as compared to ASD/FPIES monocytes (>2 fold)

${ }^{2}$ Transcripts of CCL3, IL-1B, IL-23A, and IL-6 in ASD-IS monocytes were all down-regulated as compared to the ASD/non-FPIES monocytes ( $>2$ fold). Gene expression of IL-23A and IL-6 in ASD/FPIES monocytes were down regulated 6.4 and 4.9 fold, respectively, than ASD/non-FPIESPB monocytes.

${ }^{3}$ As compared to normal controls, ASD/non-FPIES monocytes revealed up-regulation of IL-23A (5.4 fold) as well down-regulation of CCL7 (chemockine- 5.4 fold). CCL7 expression was also downregulated as compared to ASD-IS as well as ASD/FPIES monocytes ( $>2$ fold).

Table 3. Transcription profiling data in the study subjects.

\section{Discussion}

FPIES was first reported in 1940's and has been recognized as a relatively benign condition that shows good responses to avoidance measures. However, delayed onset of symptoms and lack of readily (commercially) available diagnostic measures hinders early diagnosis and early intervention. This is especially true for children with impaired expressive language, such as ASD children. For example, it has been our observation that behavioral changes associated with GI discomfort and pain are often attributed to be just 'being autistic', despite presence of objective GI symptoms. In previous years, we have attempted to sort out whether FPIES is prevalent in ASD children and if so, how FPIES affects their behavioral symptoms. Our previous results indicated a high prevalence of FPIES in ASD children, probably partly due to delayed diagnosis and treatment (Jyonouchi, 2010; Jyonouchi $\mathrm{H}$, 2007). We also observed changes of behaviors after resolution of GI symptoms when behavioral changes were assessed using the Aberrant Behavior Check list (ABC) (Jyonouchi, 2010; Jyonouchi H, 2007). 
Impaired Oral Tolerance in ASD Children with Food Protein Induced Enterocolitis Syndrome (FPIES) - Altered Innate and Adaptive Immune Responses in ASD Children...

\begin{tabular}{|c|c|c|c|}
\hline Group & $\begin{array}{l}\text { GO } \\
\text { ID }\end{array}$ & GO Term & $\begin{array}{l}\text { Corrected } \\
\text { p value }\end{array}$ \\
\hline $\begin{array}{l}\text { ASD-IS } \\
\text { vs. ASD/FPIES }\end{array}$ & $\begin{array}{l}3290 \\
3593 \\
8215 \\
8217\end{array}$ & $\begin{array}{l}\text { Oxygen transporter activity } \\
\text { Hemoglobin complex } \\
\text { Gas transport } \\
\text { Oxygen transport }\end{array}$ & $\begin{array}{l}0.02578 \\
0.02578 \\
0.01368 \\
0.02578\end{array}$ \\
\hline $\begin{array}{l}\text { ASD-IS } \\
\text { vs. ASD/non- } \\
\text { FPIES }\end{array}$ & \begin{tabular}{|c|}
4528 \\
6431 \\
19583 \\
\end{tabular} & $\begin{array}{l}\text { Response to stress } \\
\text { Response to wounding } \\
\text { Positive regulation of cell adhesion }\end{array}$ & $\begin{array}{l}0.06276 \\
0.06276 \\
0.02184 \\
\end{array}$ \\
\hline $\begin{array}{l}\text { ASD-IS } \\
\text { vs. controls }\end{array}$ & & & NS \\
\hline $\begin{array}{l}\text { ASD/FPIES } \\
\text { vs. ASD/non- } \\
\text { FPIES }\end{array}$ & $\begin{array}{c}801 \\
936 \\
1402 \\
1465 \\
3128 \\
3145 \\
3430 \\
4518 \\
4528 \\
4529 \\
4531 \\
4532 \\
5082 \\
5098 \\
5114 \\
6425 \\
6431 \\
7346 \\
10575 \\
\\
12106 \\
13736 \\
15920 \\
16941 \\
17002 \\
17201 \\
17250 \\
19242 \\
19243 \\
\\
19628 \\
22266 \\
22267 \\
23421 \\
23697 \\
23761 \\
23762\end{array}$ & $\begin{array}{l}\text { G-protin-coupled receptor binding } \\
\text { Positive regulation of cytokine production } \\
\text { Immune system process } \\
\text { Chronic inflammatory response to antigenic stimulus } \\
\text { Receptor binding } \\
\text { Cytokine activity } \\
\text { Extracellular space } \\
\text { Chemotaxis } \\
\text { Response to stress } \\
\text { Defense response } \\
\text { Inflammatory response } \\
\text { Immune response } \\
\text { Behavior } \\
\text { Locomotry behavior } \\
\text { Chemokine activity } \\
\text { Response to external stimulus } \\
\text { Response to wounding } \\
\text { Regulation of vascular endotheial growth factor production } \\
\text { Cytokine and chemokine mediated signaling pathway } \\
\text { Nitric oxide transport } \\
\text { Positive regulation of synaptic plasticity } \\
\text { Positive regulation of heterotype cell-cell adhesion } \\
\text { Regulation of cytokine biosynthetic process } \\
\text { Positive regulation of cytokine biosynthetic process } \\
\text { Taxis } \\
\text { Chemokine receptor binding } \\
\text { Regulation of nitric oxide biosynthetic process } \\
\text { Positive regulation of nitric oxide biosynthetic process } \\
\text { Positive regulation of mitosis } \\
\text { Regulation of smooth muscle cell proliferation } \\
\text { Positive regulation of smooth muscle cell proliferation } \\
\text { Response to stimulus } \\
\text { Positive regulation of nitrogen compound metabolic process } \\
\text { Regulation of muticellular organismal process } \\
\text { Positive regulation of muticellular organismal process }\end{array}$ & $\begin{array}{l}0.06068 \\
0.06644 \\
0.03348 \\
0.05304 \\
0.05304 \\
3.75 \mathrm{E}-04 \\
0.03299 \\
0.00644 \\
2.43 \mathrm{E}-05 \\
2.45 \mathrm{E}-08 \\
2.14 \mathrm{E}-08 \\
3.75 \mathrm{E}-04 \\
0.05386 \\
0.03956 \\
0.00822 \\
1.25 \mathrm{E}-05 \\
2.15 \mathrm{E}-08 \\
0.06512 \\
0.03138 \\
\\
0.05304 \\
0.05304 \\
0.05304 \\
0.05304 \\
0.05613 \\
0.00644 \\
0.00918 \\
0.06068 \\
0.03956 \\
0.05304 \\
0.03956 \\
0.00822 \\
0.07731 \\
0.05304 \\
0.05304 \\
0.03348\end{array}$ \\
\hline
\end{tabular}

Table 4. GO analysis results in the study subjects 
However, among ASD children with FPIES, there exists a subset of children who are also vulnerable to recurrent infection and have history of adverse reactions to multiple medications and other substances. These children are sensitive to a variety of food proteins and often require the intake of extremely hydrolyzed hypoallergic formulas to get sufficient nutrition, in our experience. Parents of these children also reports fluctuating behavioral symptoms and cognitive skills following immune insults, such as viral syndrome. Our previous studies indicated that these children, with fluctuating behaviors, often exhibit distinct innate immune abnormalities (Jyonouchi et al., 2008). Further analysis of this population led to the finding that ASD children with these clinical phenotypes, as well as 'treatment-resistant' FPIES, do reveal more significant changes in innate immunity which can be detected using bioassays as well as transcript profiles in $\mathrm{PB}$ monocytes (manuscript in press). We have categorized this group of ASD children as ASD-immune subtype (ASD-IS), since they appear to reveal different immune abnormalities than ASD/FPIES as well as ASD/non-FPIES children. These children also seem to be vulnerable to dysbiosis, since their GI symptoms, as well as behavioral symptoms, tend to improve following anti-fungal treatment and/or antibiosis targeting pathogenic microbes in the gut. Unfortunately, as reported by others (Sandler et al., 2000), these effects are generally transient.

It remains unclear as to how such clinical phenotypes are associated with innate and adaptive immune responses and how their immune responses are different from those observed in ASD/FPIES and non-ASD/FPIES children. To address this question, we conducted detailed studies of innate and adaptive immune responses in ASD-IS children in comparison with ASD/FPIES, non-ASD/FPIES, ASD/non-FPIES, and normal controls. Since the presence of active GI inflammation is likely to affect the bioassay results, we conducted these assays after FPIES subjects were appropriately treated with avoidance measures and nutritional supplements if required. Co-morbid conditions summarized in Table 2 in our study groups revealed that ASD-IS children do seem to have a higher prevalence of COM/CRS than other study groups, although prevalence of atopic disorders does not appear to be altered significantly among the study groups, indicating that atopy or Th2 deviated responses are unlikely to be associated with their clinical characteristics.

When we assessed innate immune responses in the study groups, our results revealed lower TNF- $\alpha$ and IL-12 production with a TLR4 agonist (LPS) than normal controls in the ASD/FPIES group. In the colon where microbes reside at the highest concentration, responses to endotoxin such as LPS are suppressed - so-called LPS desensitization (Abreu et al., 2005; Michalek et al., 1982; Smith and Nagler-Anderson, 2005; Wannemuehler et al., 1982). Tendency for lower responses to LPS in ASD/FPIES children may be beneficial for maintaining oral tolerance after recovering from FPIES. Although it was not significant, the same tendency was observed in non-ASD/FPIES children.

In ASD-IS children, while their LPS responses are equivalent to those of normal controls, spontaneous production of IL-1ß and IL-12 production with a TLR9 agonist was markedly lower. IL-1ß production with a dectin 1 agonist (heat killed candida) was also lower in the ASD-IS children. Lower production of IL-6 (without stimuli and with TLR9 agonist) and IL23 (with a TLR4 agonist) were observed in both ASD/FPIES and ASD-IS children but this was more evident in ASD-IS children. On the other hand, non-ASD/FPIES children were noted to have higher TGF- $\beta$ with a TLR2/ 6 agonist (zymosan). IL-1B, IL-6, and IL-23 are all important for differentiation and maintenance of Th17 cells as a part of their pleiotropic biological actions (Kimura and Kishimoto, 2010; Zhou et al., 2009). While IL-12 has a key role in Th1 cell differentiation. Given these findings, it may be questioned whether ASD-IS, as well as ASD/FPIES children, have impaired development of Th17 cells. When we tested frequency of IL-17+ Th cells after stimulation of PBMCs with SEB overnight, frequency of 
Th17 cells was lower in ASD/FPIES children than normal controls, but this was not evident in the ASD-IS children. Both ASD-IS and ASD/FPIES children revealed a little lower frequency of IFN- $\gamma^{+}$Th1 cells. However, to our surprise, IL-17 production in response to food proteins was higher in the ASD-IS children. Comparative frequency of Th17 cells, but higher IL-17 production in the ASD-IS children indicate that committed Th17 cells may keep producing a large amount of IL-17. These findings also indicate that excessive IL-17 responses in ASD-IS children may be associated with dysregulated development and maintenance of Th17 cells. In addition, persistent IL-17 responses will not aid in and may hinder establishment of gut immune homeostasis consistent with clinical phenotype of 'treatment-resistant' FPIES in the ASD-IS children.

In contrast to the ASD-IS group, non-ASD/FPIES children recovering from FPIES revealed higher TGF- $ß$ with a TLR2/6 agonist (zymosan). These children did not reveal an increase in frequency of Th17 cells or IL-17 production. Since TGF- $B$ regulates (down-regulates) various immune responses and also serves as a key differentiation factor for regulatory $\mathrm{T}$ (Treg) cells, especially in the absence of inflammatory cytokines (Burgler et al., 2009; Zhou et al., 2009), it may be wondered whether ASD-IS children and in some-degree, ASD/FPIES children have impaired development or function of regulatory T cells. In the GI mucosa, IL10 and TGF- $\$$ producing Treg cells are believed to have a major role in the gut immune homeostasis (Lee and Mazmanian, 2010). In that regard, non-ASD/FPIES children and perhaps ASD/FPIES children who did not reveal excessive IL-17 responses may be in the process of establishing gut mucosal immune homeostasis, while recovering from FPIES.

In the gut mucosa, it became known that Th17 cell develop prior to antigen exposure, bearing an important role in mucosal immune defense. However, following antigenexposure, regulatory $\mathrm{T}$ cells develops, developing immune homeostasis in the gut. During this process, the gut microbiota is believed to have an pivotal role in developing gut immune homeostasis affecting plasticity of $\mathrm{Th}$ cell and regulatory $\mathrm{T}$ cell development (Atarashi et al., 2011; Lee and Mazmanian, 2010; Lochner et al., 2011; Zhou et al., 2009). Consistent with this assumption, we also found that spontaneous IL-10 production, as well as that in response to luminal antigens (food proteins and candida Ag), were equivalent in non-ASD/FPIES children in comparison with normal controls. While ASD-IS children revealed lower IL-10 production, in the absence of stimuli and with candida Ag. These results again indicate that tolerance induction or establishment of immune homeostasis may be impaired in the ASD-IS children. However, it needs to be cautioned that further studies are necessary to explore this possibility, including testing gut mucosal expression of Th lineage cells in these patients. As previously stated, ASD-IS children are clinically characterized with markedly fluctuating behavioral and cognitive activity. Our findings also indicate the possibility that in addition to impairment of gut immune homeostasis, systemic immune homeostasis may also be dysregulated in the ASD-IS children. This may be the results of chronic gut inflammation or uncontrolled inflammatory responses.

To further assess changes in innate immunity, we also studies transcript profiles of PB monocytes in the study groups. However, partly due to the restriction of approved protocol, we were not able to conduct such a study in the non-ASD/FPIES children. Nevertheless, our results indicated a significantly altered gene expression in PB macrophages in the ASD-IS children. The numbers of genes with $>2$ fold up- or down-regulated expression was the highest when compared to normal controls and least when compared to ASD/FPIES children. This is not surprising, given the fact that ASD-IS and ASD/FPIES children both suffered from FPIES and gut inflammation. However, what was surprising is that the significant differences in transcript profiles of PB monocytes between ASD/non-FPIES and normal controls. These results also indicate that ASD/non-FPIES children may have altered 
immune responses or other changes that can be reflected in PB monocytes. This seems to be consistent with the results of the GO analysis, which revealed significant changes between ASD/FPIES and ASD/non-FPIES children. Involved pathways revealed differences with GO analysis are largely associated with immune/inflammatory responses as well as cytokines and chemokines, possibly reflecting fundamental differences in the 2 study groups. It should be noted that recent genetic studies have been accumulating evidence that ASD is a behavioral syndrome encompassing markedly heterogeneous populations (Bale et al., 2010; Rudan, 2010; Toro et al., 2010). Our findings also support results of previous genetic studies. However, we have to be cautious about the results given the low number of study subjects that underwent this analysis.

With transcription profiling, we also found that certain cytokines, notably IL-6, IL-1B, and IL-23, were down regulated in ASD-IS children, as compared to ASD/non-FPIES children. ASD/FPIES children also revealed down-regulation of IL-6 and IL-23. Interestingly, downregulation of IL-6 was more prominent in ASD/FPIES children, despite the fact that in vitro IL-6 protein production was lower in the ASD-IS children. In addition, GO analysis revealed significant differences between ASD/FPIES and ASD/non-FPIES groups, although given clinical features, one can expect that differences may be more prominent between ASD/IS and ASD/non-FPIES children. Our findings may indicate an importance of posttranscriptional regulation including ones exerted by microRNA (Baltimore et al., 2008).

The notable weakness of this study is lack of data of transcription profiling in the nonASD/FPIES children. This was secondary to the restriction imposed by the IRB and lack of funding. In the future, it will be interesting to compare transcript profiles between ASDIS/ASD-FPIES and non-ASD/FPIES children which may yield further important information.

\section{Conclusion}

In summary, our results indicate that altered adaptive and innate immune responses are observed in both ASD-IS and ASD/FPIES children but difference exist between the ASD-IS and ASD/FPIES children. In addition, these changes also differed from those observed in non-ASD/FPIES children. Our findings thus indicate that changes in innate and adaptive immunity observed in ASD-IS children and in some degree even in ASD/FPIES children, are not likely to be attributed to FPIES but may be associated with impaired establishment of immune homeostasis, perhaps, affected by aberrant innate immune responses.

\section{Acknowledgment}

This study was partly funded by Jonty Foundation, St. Paul, MN, and Autism Research Institute, San Diego, CA. We are also thankful for critical review by Dr. Lisa Huguienin.

\section{References}

Abreu, M.T.; Fukata, M., \& Arditi, M. (2005). TLR signaling in the gut in health and disease. Journal of Immunolology, Vol.174, No. 8, (April 2005), pp. 4453-4460, ISSN 0022-1767

Akinbami, L.J.; Moorman, J.E., \& Liu, X. (2011). Asthma prevalence, health care use, and mortality: United States, 2005-2009. National Health State Report, No. 32, (January 2011), pp. 1-14,

http:// www.ncbi.nlm.nih.gov/pubmed/21355352?dopt=Citation

Atarashi, K., Tanoue, T., Shima, T., Imaoka, A., Kuwahara, T., Momose, Y., Cheng, G., Yamasaki, S., Saito, T., Ohba, Y., 
Bale, T.L., Baram, T.Z., Brown, A.S., Goldstein, J.M., Insel, T.R., McCarthy, M.M., Nemeroff, C.B., Reyes, T.M., Simerly, R.B.,

Baltimore, D., Boldin, M.P., O'Connell, R.M., Rao, D.S., \& Taganov, K.D. (2008). MicroRNAs: new regulators of immune cell development and function. Nature Immunolology, Vol. 9, No. 8, (August 2008), pp. 839-845, ISSN 1529-2916

Buie, T., Campbell, D.B., Fuchs, G.J., 3rd, Furuta, G.T., Levy, J., Vandewater, J., Whitaker, A.H., Atkins, D., Bauman, M.L.,

Beaudet, A.L., Carr, E. G., Gershon, M. D., Hyman, S. L., Jirapinyo, P., Jyonouchi, H., Kooros, K., Kushak, R., Levitt, P., Levy, S. E., Lewis, J. D., Murray, K. F., Natowicz, M. R., Sabra, A., Wershil, B. K., Weston, S. C., Zeltzer, L., Winter, H. (2010). Evaluation, diagnosis, and treatment of gastrointestinal disorders in individuals with ASDs: a consensus report. Pediatrics Vol. 125, Suppl 1, (January 2010), pp. S118 ISSN 1098-4275

Burgler, S., Ouaked, N., Bassin, C., Basinski, T.M., Mantel, P.Y., Siegmund, K., Meyer, N., Akdis, C.A. \& Schmidt-Weber, C.B. (2009). Differentiation and functional analysis of human T(H)17 cells. Journal of Allergy and Clinical Immunology, Vol. 123, No. 3, (March 2009), pp. 588-595, ISSN 1097-6825

Butrus, S, \& Portela, R. (2005). Ocular allergy: diagnosis and treatment. Ophthalmology Clininics of North America, Vol. 18,No. 4, (December 2005), pp. 485-492, ISSN 896-1549

Jyonouchi, H. (2008). Non-IgE mediated food allergy. Inflammation and Allergy Drug Targets, Vol. 7, No. 3, (September 2008),pp. 173-180, ISSN 1871-5281

Jyonouchi, H. (2010). Autism spectrum disorders and allergy: observation from a pediatric allergy/immunology clinic. Expert Review of Clininical Immunology, Vol. 6, No. 3, (May 2010), pp. 397-411, ISSN 1774-8409

Jyonouchi, H.; Geng, L., Cushing-Ruby, A., and Quraishi, H. (2008). Impact of innate immunity in a subset of children with autism spectrum disorders: a case control study. J Neuroinflammation Vol. 5, No. 5, (November, 2008), pp. 52, ISSN 1742-2094

Jyonouchi, H.; Geng, L., Ruby, A., Reddy, C., \& Zimmerman-Bier, B. (2005). Evaluation of an association between gastrointestinal symptoms and cytokine production against common dietary proteins in children with autism spectrum disorders. Journal of Pediatrics, Vol. 146, No. 5, (May 2005), pp. 605-610, ISSN 0022-3476

Jyonouchi, H.; Geng, L., Ruby, A. \& Reddy, C. (2007). Suboptimal responses to dietary intervention in children with autism spectrum disorders and Non-IgE mediated food allergy. In: Autism Research Advance, L B Zhao (Ed), pp. 169-184.Nova Science Publishers, ISBN 1-60021-523-8.New York, NY

Jyonouchi, H.; Sun, S., \& Le, H. (2001). Proinflammatory and regulatory cytokine production associated with innate and adaptive immune responses in children with autism spectrum disorders and developmental regression. Journal of Neuroimmunology, Vol. 120, No. 1-2, (November, 2001), pp. 170-179, ISSN 0165-5728

Karlsson, M.R.; Rugtveit, J. \& Brandtzaeg, P. (2004). Allergen-responsive CD4+CD25+ regulatory $\mathrm{T}$ cells in children who have outgrown cow's milk allergy. Journal of Experimental Medicine, Vol. 199, No. 12, (June 2004), pp. 1679-1688, ISSN 0022-1007

Kimura, A. \& Kishimoto, T. (2010). Th17 cells in inflammation. International Immunopharmacology, Vol. 11, No. 3, (March, 2011), pp. 319-322, ISSN 1878-1705

Lee, Y.K. \& Mazmanian, S.K. (2010). Has the microbiota played a critical role in the evolution of the adaptive immune system? Science, Vol. 330, No. 6012, (December 2010), pp. 1768-1773, ISSN 1095-9203

Lochner, M.; Berard, M., Sawa, S., Hauer, S., Gaboriau-Routhiau, V., Fernandez, T.D., Snel, J., Bousso, P., Cerf-Bensussan, N. \& Eberl, G. (2011). Restricted microbiota and absence 
of cognate TCR antigen leads to an unbalanced generation of Th1 cells. Journal of Immunolology, Vol. 186, No. 3, (February 2011), pp. 1531-1537, ISSN 1550-6606

Michalek, S.M.; Kiyono, H., Wannemuehler, M.J., Mosteller, L.M. \& McGhee, J.R. (1982). Lipopolysaccharide (LPS) regulation of the immune response: LPS influence on oral tolerance induction. Journal of Immunology, Vol. 128, No. 5, (May 1982), pp. 19921998, ISSN 0022-1767

Nassef, M.; Shapiro, G. \& Casale, T.B. (2006). Identifying and managing rhinitis and its subtypes: allergic and nonallergic components--a consensus report and materials from the Respiratory and Allergic Disease Foundation. Current Medical Research and Opinion, Vol. 22, No. 12, (December 2006), pp. 2541-2548, ISSN 1473-4877

National Heart, Lung, and Blood Institute; National Asthma Education and Prevention Program (2007). Expert Panel Report 3 (ER3) Guidelines for the diagnosis and management of asthma, L. National Heart, and Blood Institute, ed. No. 08-4051, (Bethesda, NIH Publication).

http://www.nhlbi.nih.gov/guidelines/asthma/asthgdln.htm

Nowak-Wegrzyn, A. \& Muraro, A. (2009). Food protein-induced enterocolitis syndrome. Current Opinions in Allergy and Clinical Immunology, Vol. 9, No. 4, (August, 2009), pp. 371-377, ISSN 1473-6322

Rudan, I. (2010). New technologies provide insights into genetic basis of psychiatric disorders and explain their co-morbidity. Psychiatria Danubina, Vol. 22, No. 2, (June 2010), pp. 190-192, ISSN 0353-5053

Sandler, R.H.; Finegold, S.M., Bolte, E.R., Buchanan, C.P., Maxwell, A.P., Vaisanen, M.L., Nelson, M.N. \& Wexler, H.M (2000). Short-term benefit from oral vancomycin treatment of regressive-onset autism. Journal of Child Neurology, Vol. 15, No. 7, (July 2000), pp. 429-435, ISN 0883-0738

Schirbel, A. and Fiocchi, C. (2010). Inflammatory bowel disease: Established and evolving considerations on its etiopathogenesis and therapy. Journal of Digestive Diseases, Vol. 11, No. 5, (October, 2010), pp. 266-276, ISSN 1751-2980

Sicherer, S.H.; Eigenmann, P.A. \& Sampson, H.A. (1998). Clinical features of food proteininduced enterocolitis syndrome. Journal of Pediatrics, Vol. 133, No. 2, (August, 1998), pp. 214-219, ISSN 0022-3496

Sicherer, S.H. \& Sampson, H.A. (2006). 9. Food allergy. Journal of Allergy and Clinical Immunology, Vol. 117, 2 suppl Mini-Primer, pp. S470-475, ISSN 0091-6749

Singh, K.; Axelrod, S. \& Bielory, L. (2010). The epidemiology of ocular and nasal allergy in the United States, 1988-1994. Journal of Allergy and Clinical Immunology, Vol. 126, No. 4, (October, 2010), pp. 778-783 e776, ISSN 1097-6825

Smith, D.W. \& Nagler-Anderson, C. (2005). Preventing intolerance: the induction of nonresponsiveness to dietary and microbial antigens in the intestinal mucosa. Journal of Immunology, Vol. 174, No. 7, (April, 2005), pp. 3851-3857, ISSN 0022-1767

Toro, R.; Konyukh, M., Delorme, R., Leblond, C., Chaste, P., Fauchereau, F., Coleman, M., Leboyer, M., Gillberg, C. \& Bourgeron, T. (2010). Key role for gene dosage and synaptic homeostasis in autism spectrum disorders. Trends in Genetics, Vol. 26, No. 8, (August, 2010), pp. 363-372, ISSN 0168-9525

Wannemuehler, M.J.; Kiyono, H., Babb, J.L., Michalek, S.M. \& McGhee, J.R. (1982). Lipopolysaccharide (LPS) regulation ofthe immune response: LPS converts germfree mice to sensitivity to oral tolerance induction. Journal of Immunolology, Vol. 129, No. 3, (September, 1982), pp. 959-965, ISSN 0022-1767

Zhou, L.; Chong, M.M. \& Littman, D.R. (2009). Plasticity of CD4+ T cell lineage differentiation. Immunity Vol. 30, No. 5,(May, 2009), pp. 646-655, ISSN 1097-4180 


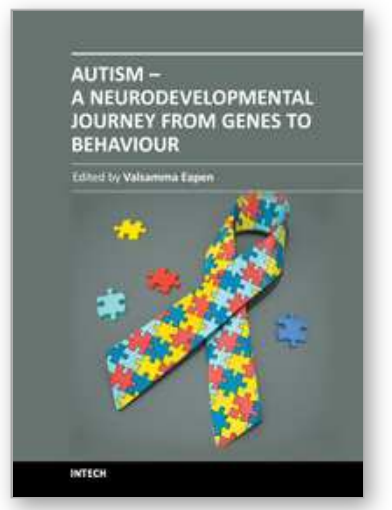

\author{
Autism - A Neurodevelopmental Journey from Genes to Behaviour \\ Edited by Dr. Valsamma Eapen
}

ISBN 978-953-307-493-1

Hard cover, 484 pages

Publisher InTech

Published online 17, August, 2011

Published in print edition August, 2011

The book covers some of the key research developments in autism and brings together the current state of evidence on the neurobiologic understanding of this intriguing disorder. The pathogenetic mechanisms are explored by contributors from diverse perspectives including genetics, neuroimaging, neuroanatomy, neurophysiology, neurochemistry, neuroimmunology, neuroendocrinology, functional organization of the brain and clinical applications from the role of diet to vaccines. It is hoped that understanding these interconnected neurobiological systems, the programming of which is genetically modulated during neurodevelopment and mediated through a range of neuropeptides and interacting neurotransmitter systems, would no doubt assist in developing interventions that accommodate the way the brains of individuals with autism function. In keeping with the multimodal and diverse origins of the disorder, a wide range of topics is covered and these include genetic underpinnings and environmental modulation leading to epigenetic changes in the aetiology; neural substrates, potential biomarkers and endophenotypes that underlie clinical characteristics; as well as neurochemical pathways and pathophysiological mechanisms that pave the way for therapeutic interventions.

\title{
How to reference
}

In order to correctly reference this scholarly work, feel free to copy and paste the following:

Harumi Jyonouchi, Lee Geng, Pamella Kattouf, Deanna L. Streck and Gokce Toruner (2011). Impaired Oral Tolerance in ASD Children with Food Protein Induced Enterocolitis Syndrome (FPIES) - Altered Innate and Adaptive Immune Responses in ASD Children Recovered from FPIES in Comparison with non-ASD/FPIES and ASD/non-FPIES Children, Autism - A Neurodevelopmental Journey from Genes to Behaviour, Dr. Valsamma Eapen (Ed.), ISBN: 978-953-307-493-1, InTech, Available from: http://www.intechopen.com/books/autism-aneurodevelopmental-journey-from-genes-to-behaviour/impaired-oral-tolerance-in-asd-children-with-foodprotein-induced-enterocolitis-syndrome-fpies-alter

\section{INTECH}

open science | open minds

\author{
InTech Europe \\ University Campus STeP Ri \\ Slavka Krautzeka 83/A \\ 51000 Rijeka, Croatia \\ Phone: +385 (51) 770447 \\ Fax: +385 (51) 686166
}

\author{
InTech China \\ Unit 405, Office Block, Hotel Equatorial Shanghai \\ No.65, Yan An Road (West), Shanghai, 200040, China \\ 中国上海市延安西路65号上海国际贵都大饭店办公楼 405 单元 \\ Phone: +86-21-62489820 \\ Fax: +86-21-62489821
}


www.intechopen.com 
(C) 2011 The Author(s). Licensee IntechOpen. This chapter is distributed under the terms of the Creative Commons Attribution-NonCommercialShareAlike-3.0 License, which permits use, distribution and reproduction for non-commercial purposes, provided the original is properly cited and derivative works building on this content are distributed under the same license. 